Article

\title{
Insights on the Role of Copper Addition in the Corrosion and Mechanical Properties of Binary $\mathrm{Zr}-\mathrm{Cu}$ Metallic Glass Coatings
}

\author{
Junlei Tang ${ }^{1,2, *}$ (D), Qiuhong Zhu ${ }^{1}$, Yingying Wang ${ }^{1}$, Mihai Apreutesei ${ }^{3, *}$, Hu Wang ${ }^{4}$, \\ Philippe Steyer $^{3}$ (D), Mohamad Chamas ${ }^{1}$ and Alain Billard ${ }^{5}$ \\ 1 School of Chemistry and Chemical Engineering, Southwest Petroleum University, Chengdu 610500, China; \\ zhuqhcq@foxmail.com (Q.Z.); yingyingwanglyon@126.com (Y.W.); mochamas@gmail.com (M.C.) \\ 2 State Key Laboratory of Oil and Gas Reservoir Geology and Exploitation, Southwest Petroleum University, \\ Chengdu 610500, China \\ 3 MATEIS Laboratory-UMR CNRS 5510, Université de Lyon, INSA-Lyon, 7 Avenue Jean Capelle, \\ 69621 Villeurbanne CEDEX, France; philippe.steyer@insa-lyon.fr \\ 4 School of Material Science and Engineering, Southwest Petroleum University, Chengdu 610500, China; \\ enty78@126.com \\ 5 Institut FEMTO-ST, CNRS, UTBM, University Bourgogne Franche-Comté, Site de Montbéliard, \\ 90010 Belfort CEDEX, France; alain.billard@utbm.fr \\ * Correspondence: tangjunlei@126.com (J.T.); mihai.projects@gmail.com (M.A.); Tel.: +86-18608039391 (J.T.) \\ Academic Editor: Alessandro Lavacchi \\ Received: 26 September 2017; Accepted: 17 November 2017; Published: 5 December 2017
}

\begin{abstract}
The effect of copper addition on the corrosion resistance and mechanical properties of binary $\mathrm{Zr}_{100-x} \mathrm{Cu}_{x}(x=30,50,80,90$ at.\%) glassy coatings was investigated by means of electrochemical measurements, scanning electron microscopy (SEM), energy dispersive analysis spectroscopy (EDS), X-ray photoelectron spectroscopy (XPS) and nano-indentation techniques. The corrosion resistance in $0.01 \mathrm{M}$ deaerated $\mathrm{H}_{2} \mathrm{SO}_{4}$ solution and the mechanical properties of the $\mathrm{Zr}$-Cu glassy coatings depend considerably upon the copper content in the glassy matrix. The top surfaces of the $\mathrm{Zr}-\mathrm{Cu}$ coatings with lower $\mathrm{Cu}$ content were covered by a compact protective $\mathrm{ZrO}_{2}$ passive film. The competition between the oxidation of $\mathrm{Zr}$ atoms $\left(\mathrm{ZrO}_{2}\right.$ film formation) and the oxidation-dissolution of $\mathrm{Cu}$ atoms assumed the most important role in the electrochemical behavior of the $\mathrm{Zr}-\mathrm{Cu}$ glassy coatings. The generation of $\mathrm{ZrO}_{2}$ on the surface benefited the formation of passive film; and the corrosion resistance of the metallic glass coatings depended on the coverage degree of $\mathrm{ZrO}_{2}$ passive film. The evolution of free volume affected both the mechanical and corrosion behaviors of the $\mathrm{Zr}-\mathrm{Cu}$ glassy coatings.
\end{abstract}

Keywords: $\mathrm{Zr}-\mathrm{Cu}$ glassy coating; corrosion resistance; $\mathrm{Cu}$ addition; passive film; mechanical property

\section{Introduction}

The metallic glass-based materials including bulk (BMGs) and thin films are amorphous alloys which have recently attracted considerable attention in both fundamental and applied research. They have distinctive properties such as good corrosion resistance, extreme strength, high thermal stability and viscous flow, high glass-forming ability, or large elastic limita [1,2]. Their unique features deliver novel properties and their combination gives them an attractive potential for wide-ranging applications, e.g., as components of sporting goods, springs, detection apparatuses and information storage, case parts or protective films for portable electronic devices [3].

The excellent corrosion resistance of amorphous alloys compared with their crystalline alloy counterparts is mostly attributable to their stable chemical and structural homogeneities and lack of structural defects like grain boundaries, dislocations, secondary phases or inclusions. The homogeneity 
of amorphous alloys benefits the formation of laterally uniform passive films and eliminates the initiation of corrosion based on activated surface sites [4].

The role of structural state in the corrosion behavior of $\mathrm{Cu}-\mathrm{Zr}$ (or $\mathrm{Zr}-\mathrm{Cu}$ in some cases) amorphous alloys as a metal-metal system has been addressed in several investigations. Naka et al. [5] showed that the corrosion resistance of amorphous $\mathrm{Cu}_{50} \mathrm{Zr}_{50}$ in $\mathrm{H}_{2} \mathrm{SO}_{4}, \mathrm{HNO}_{3}, \mathrm{HCl}$ and $\mathrm{NaCl}$ solutions was higher compared with crystalline counterparts due to its better chemical homogeneity. Turn and Latanision [6] probed the influence of structure on the corrosion resistance of glassy Cu-Zr alloys in a Cu compositional domain (55 at.\% and 60 at.\% copper) in $1 \mathrm{~N}$ sulfuric acid, and found no significant effect on the general corrosion behavior. It has been also suggested that the effect of structure on the anodic polarization is much weaker with respect to alloys chemistry [6]. Bala [7] came to the same conclusion during their study on the corrosion behavior of $\mathrm{Cu}_{45} \mathrm{Zr}_{55}, \mathrm{Cu}_{50} \mathrm{Zr}_{50}$ and $\mathrm{Cu}_{60} \mathrm{Zr}_{40}$ amorphous and crystalline alloys (ribbons with $2.5 \mathrm{~mm}$ wide and $0.1 \mathrm{~mm}$ thick) in $1 \mathrm{~N}$ sulfuric acid. Their report also showed that the high $\mathrm{Cu}$ content would increase the critical passivation currents, while the chemical composition had a different effect on the anodic polarization behavior, as previously also demonstrated by Gostin et al. [8].

These phenomena might be attributed to selective dissolution of $\mathrm{Cu}$ and the passivation property of the $\mathrm{Zr}$ component; however, no further discussion nor study on the $\mathrm{Cu}-\mathrm{Zr}$ binary thin film system in a wide compositional range has been reported.

When designing BMGs many difficulties must be overcome due to poor control of chemical composition; accordingly, a compromise between functionality-oriented component design and glass formation ability is generally proposed [9]. Nevertheless, when the dimension of amorphous alloys is reduced to micro-scale, the limitations for component design would become less complex. Therefore, the amorphous alloy materials in a coating (or thin film) form have several advantages for fully designing a chemical-composition relationship without restricting the glass formation ability.

On the other hand, one of the enduring sources of interest in metallic glass-based materials is their mechanical properties, which contrast with conventional crystalline metals and make them an interesting class of engineering material $[10,11]$. Another real potential of metallic glassy coating is the possibility to overcome the macroscopic brittle-like behavior of bulk metallic glass due to its smaller dimensions. Ghidelli et al. [12] showed that at a fixed thickness the composition change in a $\mathrm{Zr}$-Ni system had a significant size effect on nanoindentation hardness, as well as the local atomic environment and elastic properties. More recently, metallic glassy coatings have received great attention for their potential utilization in microelectromechanical systems [13]. For instance, Kobata et al. explored the effect of nanofabrication of a Ti-Cu-based metallic glass system and found the optimal conditions for deposition of thin-film metallic glasses with good thermal properties and a very smooth surface for nanoimprint applications [14].

Nowadays, metallic glass coatings (or glassy coatings) are elaborated by means of physical vapor deposition (PVD) techniques [15] and have been identified as encouraging candidates to meet the industrial demand for lowering the dimensions of the components with specific characteristics (e.g., very smooth surface, high resistance under high mechanical load). By controlling sputtering parameters, glassy coatings can be successfully deposited using single metal targets with a fully homogenous composition, glassy structure, low roughness and wide super-cooled liquid region [16].

It has been previously reported that $\mathrm{Zr}-\mathrm{Cu}$ metallic glass coatings with thickness of about $5 \mu \mathrm{m}$ prepared by magnetron co-sputtering exhibited an amorphous state within the 33.3-89.1 at.\% Cu compositional range and high thermal stability at temperatures higher than $550 \mathrm{~K}$ [17]. Recently, the evolution of the structure, thermal behavior, mechanical, electrical and surface properties of $\mathrm{Zr}-\mathrm{Cu}$ coatings with $\mathrm{Cu}$ content in a wider composition range (10-90 at.\%) has been reported [18]. The corrosion behavior of this fundamental system has been only partially studied in a wide range of compositions [19]. It has been reported that $\mathrm{Zr}-\mathrm{Cu}$ films (including amorphous and crystalline ones) with 34 at. $\% \mathrm{Cu}$ or less had a good corrosion resistance in the ASTM standard salt spray test [19]. 
The $\mathrm{Cu}-\mathrm{Zr}$ nanostructured films can have different dissolution properties in $\mathrm{HCl}$ solution when increasing the $\mathrm{Zr}$ content from 15 at.\% to 66 at.\%, as reported by Lu et al. [20] Their investigation proposed a mechanism of a continuous active pathway for the $\mathrm{Zr}$ atoms' dissolution in high $\mathrm{Zr}$ content grains, and the competition between the dissolution of $\mathrm{Zr}$ and the rearrangement of $\mathrm{Cu}$ in the film.

However, a systematic investigation on the corrosion mechanism and kinetics of $\mathrm{Zr}-\mathrm{Cu}$ metallic glass coatings and $\mathrm{Zr}-\mathrm{Cu}$ binary BMGs in sulfuric acid solution, or even $\mathrm{Zr}$ based on a wide compositional range, is still lacking in the literature. It is widely accepted that the corrosion resistance of a $\mathrm{Zr}-\mathrm{Cu}$ binary system depends significantly on the passivation capability of the zirconium component, whatever its amorphous or crystalline state [5-7]. Nevertheless, it is still important to further understand the effect of copper on the corrosion mechanism in an amorphous system with minimal inhomogeneity factors (i.e., $\mathrm{Cu}_{8} \mathrm{Zr}_{3}, \mathrm{Cu}_{9} \mathrm{Zr}_{2}, \mathrm{Cu}_{10} \mathrm{Zr}_{7}, \mathrm{CuZr} 2$ etc. exist in crystalline $\mathrm{Zr}-\mathrm{Cu}$ alloys $[7,19]$ with atomic ratio changing).

Here, $\mathrm{Zr}_{100-x} \mathrm{Cu}_{x}$ glassy coatings ( $x=30,50,80,90$ at.\%) (nominal composition) were successfully prepared for finishing applications and selected in order to investigate the role of the chemical composition on corrosion behavior and mechanical properties of $\mathrm{Zr}-\mathrm{Cu}$ physical vapor deposition (PVD) metallic glass coatings.

\section{Materials and Methods}

\subsection{Material Preparation}

The binary $\mathrm{Zr}-\mathrm{Cu}$ glassy coatings were prepared by the co-sputtering PVD technique using high purity (99.6 at.\%) Zr and Cu targets in a 40-liter cylinder Alcatel 450 SCM sputtering reactor (Alliance Concept, Cran-Gevrier, France). The base pressure in the chamber before deposition was lower than $10^{-4} \mathrm{~Pa}$ and the elaboration was done at a working pressure of $0.5 \mathrm{~Pa}$ under $50 \mathrm{sccm} \mathrm{Ar}$ flow. The sputtering time was varied until a thickness of about $5 \mu \mathrm{m}$ was obtained by means of sputtering powers in a 220-260 $\mathrm{W}$ range [21]. The $\mathrm{Zr}-\mathrm{Cu}$ glassy coatings were deposited on a glass substrate in order to characterize only their intrinsic electrochemical behavior without any galvanic effect. The coatings' thickness was determined by means of an Altisurf profilometer (Altimet, Marin, France) equipped with an inductive probe using a step method performed on glass slides. In order to confirm the thickness, perpendicular fractured scanning electron microscopy (SEM) cross-section analysis was performed on coatings deposited on the Si substrate.

\subsection{Electrochemical Measurements}

Electrochemical measurements were carried out by a standard three-electrode system with a reference electrode of $\mathrm{Hg} / \mathrm{HgSO}_{4}$ in saturated $\mathrm{H}_{2} \mathrm{SO}_{4}$ solution (hereafter referred to as MMSE, $0 \mathrm{~V}_{\mathrm{MMSE}}=0.616 \mathrm{~V}_{\mathrm{NHE}}$ ), and the counter electrode was a Pt foil with the surface of $1 \mathrm{~cm}^{2}$. The exposed area of the sample was about $0.5 \mathrm{~mm}^{2}$ and all electrochemical measurements were conducted using the CHI660E electrochemical measurement system (Shanghai Chen Hua Company, Shanghai, China). Prior to beginning the electrochemical measurements, the specimens were cathodic polarized at $-1.5 \mathrm{~V}$ for $300 \mathrm{~s}$ to remove the natural oxide film formed in air.

Potentiodynamic polarization curves were performed with a potential sweep rate of $0.5 \mathrm{mV} / \mathrm{s}$ from $-0.2 \mathrm{~V}$ below open circuit potential $(\mathrm{OCP})$ to $1.8 \mathrm{~V}$ above $\mathrm{OCP}$ after monitoring open circuit potential (OCP) for $16 \mathrm{~h}$ in deaerated $0.01 \mathrm{M} \mathrm{H}_{2} \mathrm{SO}_{4}$ solution. Potentiostatic electrochemical impedance spectroscopy (EIS) measurements were performed at OCP every $4 \mathrm{~h}$ to analyze the corrosion evolution process. All EIS measurements were performed at a sinusoidal potential amplitude of $10 \mathrm{mV}$ and a frequency ranging from $100 \mathrm{kHz}$ to $10 \mathrm{mHz}$. The EIS data were fitted using ZSimpWin software (V3_20). The test solution was $0.01 \mathrm{M}$ sulfuric acid, which was deaerated by purified nitrogen gas for $12 \mathrm{~h}$ before and throughout each experiment. The sulfuric acid solution was prepared from regent-grade chemical and concentrated sulfuric acid mixed with distilled water. All tests were performed at ambient temperature. 


\subsection{Material Characterization}

The structural states of $\mathrm{Zr}-\mathrm{Cu}$ glassy coatings were characterized by means of $\mathrm{X}$-ray diffraction (XRD) (X Pert PRO MPD, PANalytical, Almelo, The Netherlands) using a X Pert PRO MPD diffractometer equipped with $\mathrm{Cu} \mathrm{K}_{\alpha}$ radiation $(\lambda=0.1542 \mathrm{~nm})$. The surface morphologies were characterized by means of a scanning electron microscope (ZEISS, EVO, MA15, Oberkochen, Germany) before and after immersion in $0.01 \mathrm{M}$ deaerated sulfuric acid solution. The chemical compositions were examined by energy dispersive analysis spectroscopy (EDS) (XM2 LX, EDAX, Mahwah, NJ, USA) connected to the SEM. After the corrosion experiments, the composition of the passive layer formed on the $\mathrm{Zr}$-Cu metallic glass coatings was investigated by means of X-ray photoelectron spectroscopy (XPS) (ESCALAB 250 photoelectron spectrometer-Thermo Fisher Scientific, Waltham, MA, USA) equipped with Al-k $\alpha$ radiation ( $h v=1486.6 \mathrm{eV}$ ). The XPS results were deconvoluted using the XPSPEAK software (V41) with Newton's iteration method and quantitative results were extracted from the survey spectra with respect to standard Scofield sensitivity factors [22].

\subsection{Mechanical Test}

The mechanical properties were obtained using a MTS nanoindenter XP (Agilent Technologies, Les Ulis, France) equipped with a Berkovich indenter by means of the continuous stiffness measurements (CSMs) method. The fused silica was used as reference to calibrate the Berkovich indenter. The load depth during the tests was fixed at $10 \%$ of the coatings' thickness in order to avoid the substrate effects. The hardness and Young's modulus were averaged from at least 20 measurements performed on several zones.

\section{Results}

\subsection{Structural Characterization}

Figure 1 illustrates the influence of chemical composition on the structure of $\mathrm{Zr}$-Cu glassy coatings. The broad peak between $20^{\circ}$ and $30^{\circ}$ is attributed to the glass substrate [23]. The coatings present only a broad diffraction hump for the compositions in between 30 at.\% $\mathrm{Cu}$ and 80 at.\% $\mathrm{Cu}$ with no appreciable crystal phases detected, suggesting a typical amorphous structure. It is worth mentioning that at higher $\mathrm{Cu}$ contents, the $\mathrm{Zr}-90$ at.\% Cu sample displays some crystal-like features corresponding to the pure $\mathrm{Cu}$ phase. Furthermore, it can be noted that the amorphous humps shift to higher $2 \theta$ angles by increasing the copper content. This displacement reflects the fact that $\mathrm{Zr}-\mathrm{Cu}$ glassy coatings are governed by different bonding lengths, interatomic interactions and, most clearly, by different density ratios [24].

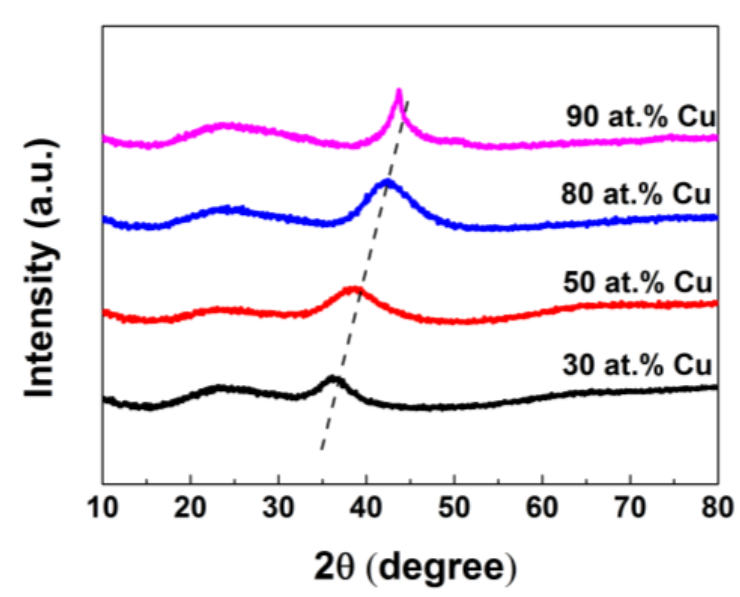

Figure 1. X-ray diffraction patterns of $\mathrm{Zr}-\mathrm{Cu}$ glassy coatings. 
Figure 2 shows the cross sections of glassy coatings with thickness. The average coating thickness of $\mathrm{Zr}-\mathrm{Cu}$ coating is about $4.9 \mu \mathrm{m}$ (Figure 2a), $4.8 \mu \mathrm{m}$ (Figure 2b), $4 \mu \mathrm{m}$ (Figure 2c) and $6.2 \mu \mathrm{m}$ (Figure 2d) as the content of copper increases from $30 \%$ to $90 \%$.
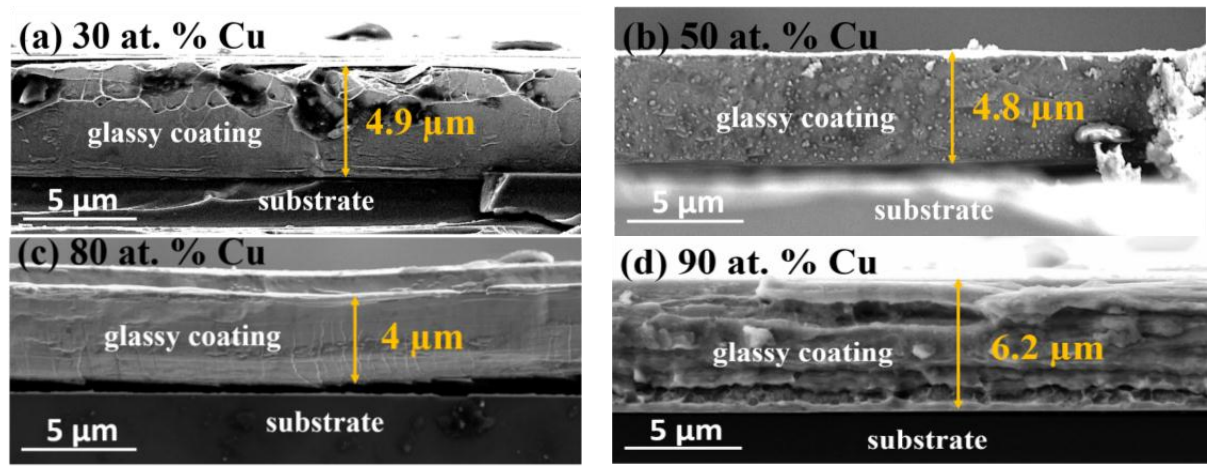

Figure 2. Scanning electron microscopy (SEM) images of cross sections of Zr-Cu glassy coatings.

\subsection{Electrochemical Corrosion Behavior}

The potentiodynamic polarization curves of $\mathrm{Zr}-\mathrm{Cu}$ coatings are shown in Figure 3 . The $E_{\text {corr }}$ potential (in the range of -1.0 to $-0.2 \mathrm{~V}_{\mathrm{MMSE}}$ ) are located at the active-passive transition region except for the $\mathrm{Zr}-30 \% \mathrm{Cu}$ sample. The Zr-30 at.\% Cu and Zr-50 at.\% Cu coatings exhibit a passive behavior in the quasi-stationary polarization state due to the formation of protective $\mathrm{ZrO}_{2}$ passive film on their surfaces in anodic polarization. $\mathrm{CuO}$ could also be produced from the dissolution of $\mathrm{Cu}$ with the following hydrolysis reaction in a sulphuric acid solution [25]. Considering that the standard equilibrium electrode potentials of $\mathrm{Zr} / \mathrm{Zr}^{4+}$ and $\mathrm{Cu} / \mathrm{Cu}^{2+}$ are $-1.904 \mathrm{~V}_{\mathrm{MMSE}}$ and $-0.038 \mathrm{~V}$ MMSE, respectively, the $\mathrm{ZrO}_{2}$ will be preferentially formed with respect to $\mathrm{CuO}$ in diluted sulphuric acid solution. The anodic polarization curve of $\mathrm{Zr}-50$ at.\% $\mathrm{Cu}$ coating indicates an active-passive transition peak approximately at $-0.25 \mathrm{~V}_{\mathrm{MMSE}}$, which is very close to the standard equilibrium electrode potential of $\mathrm{Cu} / \mathrm{Cu}^{2+}$. The increase in current density can be attributed to the oxidation-dissolution of metallic $\mathrm{Cu}$ [26]. However, the passivation can be obtained at higher anodic potential when the copper is depleted and the zirconium is enriched on the surface, as in the case of the $\mathrm{Zr}-50$ at.\% Cu coating. For the $\mathrm{Zr}-80$ at.\% Cu sample, the oxidation-dissolution of copper is found in the same potential range. However, no strong passivation appeared and the anodic current densities are close to $10^{-4} \mathrm{~A} \cdot \mathrm{cm}^{-2}$, without any obvious oscillation at higher anodic potential. The polarization curve of the $\mathrm{Zr}-90 \mathrm{at} . \% \mathrm{Cu}$ sample has a strong oxidation-dissolution peak of copper, many oscillation peaks in the anodic region and high anodic current densities $\left(10^{-3} \mathrm{~A} \cdot \mathrm{cm}^{-2}\right)$. As expected, from the potentiodynamic polarization curves, the anodic activity of the $\mathrm{Zr}-\mathrm{Cu}$ glassy coatings increases with the increase of the alloying Cu element.

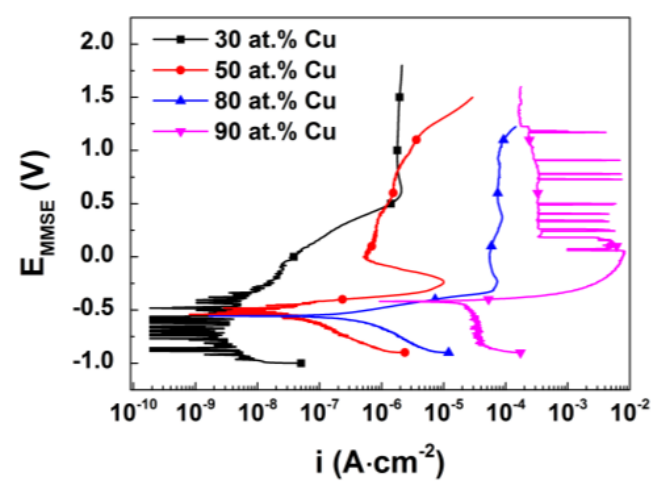

Figure 3. Potentiodynamic polarization curves of $\mathrm{Zr}-\mathrm{Cu}$ glassy coatings after holding $16 \mathrm{~h}$ open circuit potential (OCP) in $0.01 \mathrm{M}$ deaerated $\mathrm{H}_{2} \mathrm{SO}_{4}$ solution at ambient temperature. 
From the polarization curves, it can be inferred that the $\mathrm{Zr}-30$ at.\% $\mathrm{Cu}$ sample has the best passivation property, which is attributed to the oxidation of zirconium as the major anodic reaction at the corrosion potential. Therefore, increasing copper in glassy coatings will reduce the passivation ability. In order to further understand the effect of copper on the corrosion kinetics, EIS measurements were performed, and representative Nyquist diagrams and Bode plots as a function of immersion time evolution are presented in Figure 4.
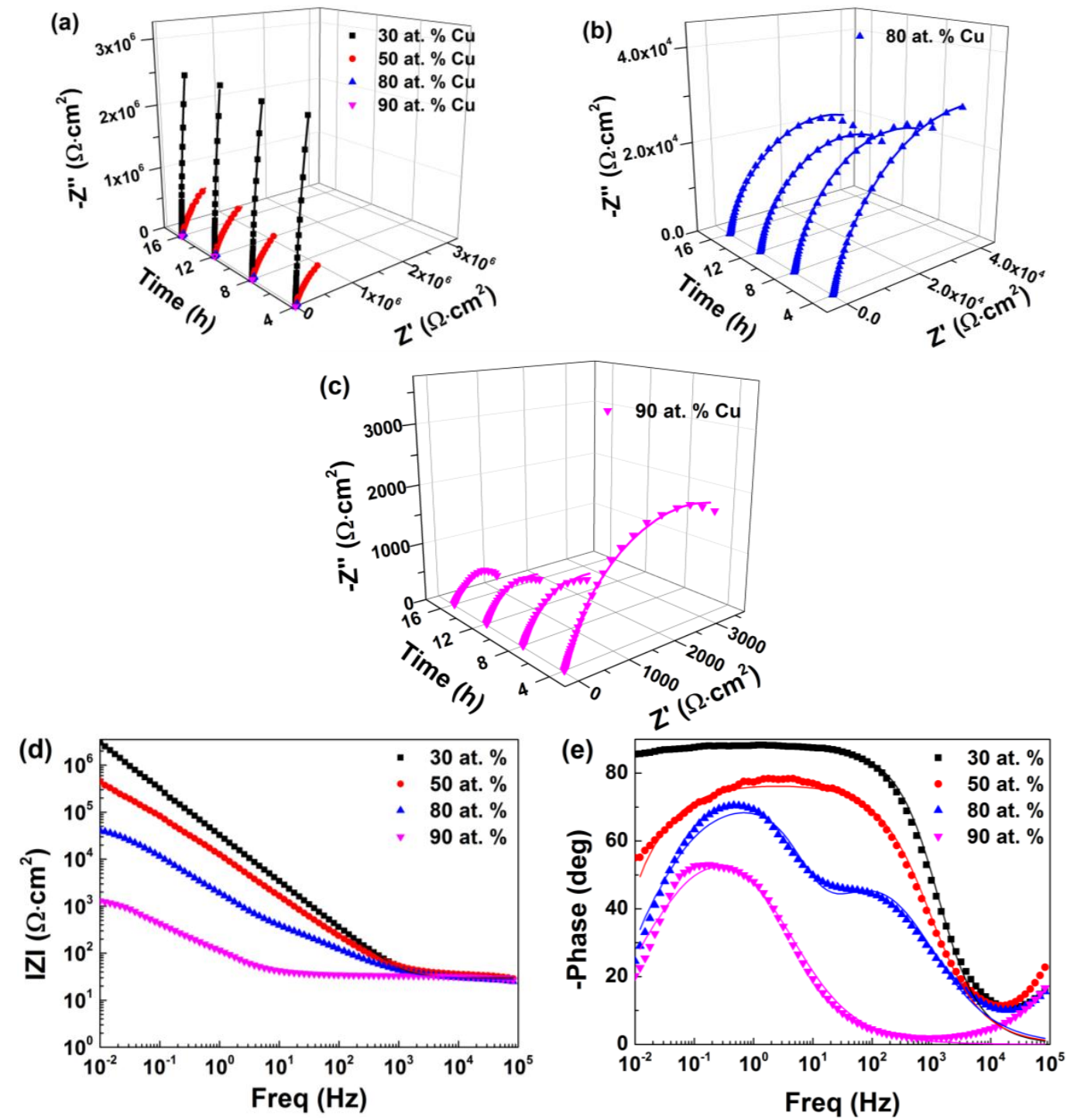

Figure 4. Electrochemical impedance spectroscopy (EIS) of $\mathrm{Zr}-\mathrm{Cu}$ glassy coatings in $0.01 \mathrm{M}$ deaerated $\mathrm{H}_{2} \mathrm{SO}_{4}$ solution at ambient temperature with different immersion time; (a) Nyquist plots of coatings' $\mathrm{Cu}$; (b) magnified Nyquist diagram of $\mathrm{Zr}-80$ at.\% Cu glassy coatings; (a,c) magnified Nyquist diagram of $\mathrm{Zr}-90$ at. $\% \mathrm{Cu} ;(\mathbf{a}, \mathbf{d}, \mathbf{e})$ Bode plots of coatings at $16 \mathrm{~h}$; the solid line represents the fitting curve.

Figure 4a-c show that the capacitive semicircles of $\mathrm{Zr}-30$ and 50 at.\% $\mathrm{Cu}$ glassy coatings increase with the extension of time; by contrast, the capacitive semicircles of $\mathrm{Zr}-80$ and 90 at. $\% \mathrm{Cu}$ glassy coatings decrease, indicating that stable passive films are formed on the surface of $\mathrm{Zr}-30$ and 50 at.\% Cu glassy coatings. Nyquist plots also show that the capacitive semicircles of glassy coatings decrease as the copper become the dominant element. Furthermore, it can be observed that the capacitive semicircles are compressive at higher $\mathrm{Cu}$ contents. This may be related to the change of electrode/electrolyte interface from rich $\mathrm{ZrO}_{2}$ to $\mathrm{CuO}$ by increasing the copper content. 
Figure $4 \mathrm{~d}$ shows that both $|\mathrm{Z}|$ and corrosion resistance decreases with the increase of $\mathrm{Cu}$ content in the matrix. Figure 4e shows that the Bode phase plots of $\mathrm{Zr}-30$ at. $\% \mathrm{Cu}$ and $\mathrm{Zr}-50$ at. $\% \mathrm{Cu}$ glassy coatings exhibit a line approximate to $-90^{\circ}$ in the middle-frequency region.

Based on electrochemical kinetics, it can be seen that glassy coatings containing 30 at.\% $\mathrm{Cu}$, 50 at.\% $\mathrm{Cu}$ and 90 at.\% Cu have mainly only one time constant, while for the $\mathrm{Zr}-80$ at.\% Cu coating, two time constants are observed. These two time constants are possibly related to oxidation and reduction reactions as it previously reported for binary $\mathrm{Zr}-\mathrm{Co} / \mathrm{Ni}$ glassy coatings [21]. Such results may indicate that the electrochemical kinetics of $\mathrm{Zr}-30$ at.\% $\mathrm{Cu}$ and $\mathrm{Zr}-50$ at. $\% \mathrm{Cu}$ are controlled by the anodic reaction, while the $\mathrm{Zr}-90$ at.\% $\mathrm{Cu}$ sample is controlled by the cathodic reaction.

The EIS data were fitted using the equivalent circuits schematically presented in Figure 5. $R_{s}$ represents the solution resistance; $\mathrm{CPE} 1$ and $R_{c t}$ are the capacitance and charge transfer resistance of the protective or corroded layer, respectively, which represents the electrolyte/oxide layer's interface. CPE2 and $R_{p}$ characterize the capacitance and resistance of electrochemical reaction at the electrolyte/glassy coating interface, respectively [27].

(a)

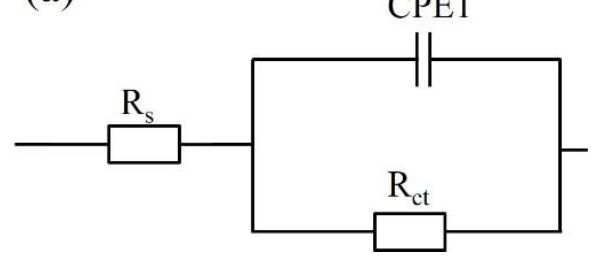

(b)

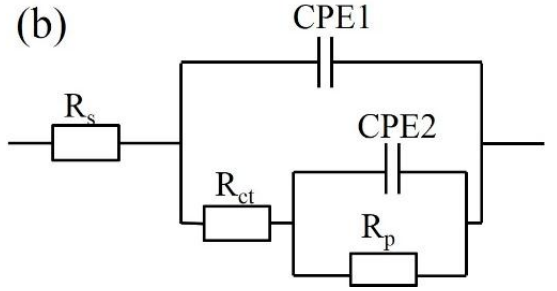

Figure 5. Equivalent electrical circuit model used to fit the EIS data; (a) is used for $\mathrm{Zr}-30 \mathrm{at} \% \mathrm{Cu}$, 50 at. \% $\mathrm{Cu}$ and 90 at. \% $\mathrm{Cu} ;(\mathbf{b})$ is used for $\mathrm{Zr}-80$ at.\% Cu, $R_{c t}$-charge transfer resistance of oxide layer, $R_{p}$-resistance of electrochemical reaction at electrolyze/glassy coating interface.

The equivalent circuit in Figure 5a was applied to fit the EIS plots of $\mathrm{Zr}-30$ at. $\% \mathrm{Cu}, 50$ at. $\% \mathrm{Cu}$ and 90 at. $\%$ Cu glassy coatings, while the EIS plot of $\mathrm{Zr}-80$ at. $\% \mathrm{Cu}$ sample was fitted using the equivalent circuit presented in Figure 5b. The average fitting error was less than 0.10 and the impedance of CPE is defined as:

$$
Z_{C P E}=\frac{1}{Q}(j \omega)^{-n}
$$

where $Q$ and $n$ are the CPE constant and exponent, respectively; $\omega$ is the angular frequency ( $\mathrm{rad} / \mathrm{s})$; and $j^{2}=-1$ is the imaginary number. The value of $n$ for CPE is $0-1 . n=1$ is for ideal capacitor and reflects a complete semi-circle. $n=0.5$ is for Warburg equipment [21].

\subsection{Corrosion Morphology and Composition Characterization}

The surface morphology and chemical composition before and after corrosion have been characterized by SEM and EDS (Figure 6). The $\mathrm{Zr}-30$ at. $\% \mathrm{Cu}$ glassy coating before and after immersion in the $\mathrm{H}_{2} \mathrm{SO}_{4}$ solution displays a smooth surface and good chemical homogeneity (Figure 6a,b). However, after immersion the $\mathrm{Zr}$ content increased slightly as found by the EDS analysis (Figure 6b). This might correspond to the enrichment of the surface with $\mathrm{Zr}$ and the passivation of glassy coating.

$\mathrm{Zr}-50$ at. $\% \mathrm{Cu}$ glassy coating has homogenous morphology before corrosion. By comparison, the film appears in two zones with different composition after immersion. Based on the darker area (Figure 6d) in zone 2, it may be implied that the surface only endured slight corrosion. The EDS analysis in this zone shows lower zirconium content (42.8 at.\%), lower $\mathrm{Cu}$ content compared with the as-deposited state, and high content of oxygen (28.2 at.\%). This indicates a preferential oxidation-dissolution of copper in this area. This highlights that the protection of $\mathrm{ZrO}_{2}$ film on the surface is reduced compared with the $\mathrm{Zr}-30$ at.\% Cu glassy coating. Nonetheless, the formation of protective $\mathrm{ZrO}_{2}$ film is possible after the preferential dissolution of copper in these corroded local areas, as implied from impedance arcs that keep increasing with immersion time evolution (Figure 4a). 


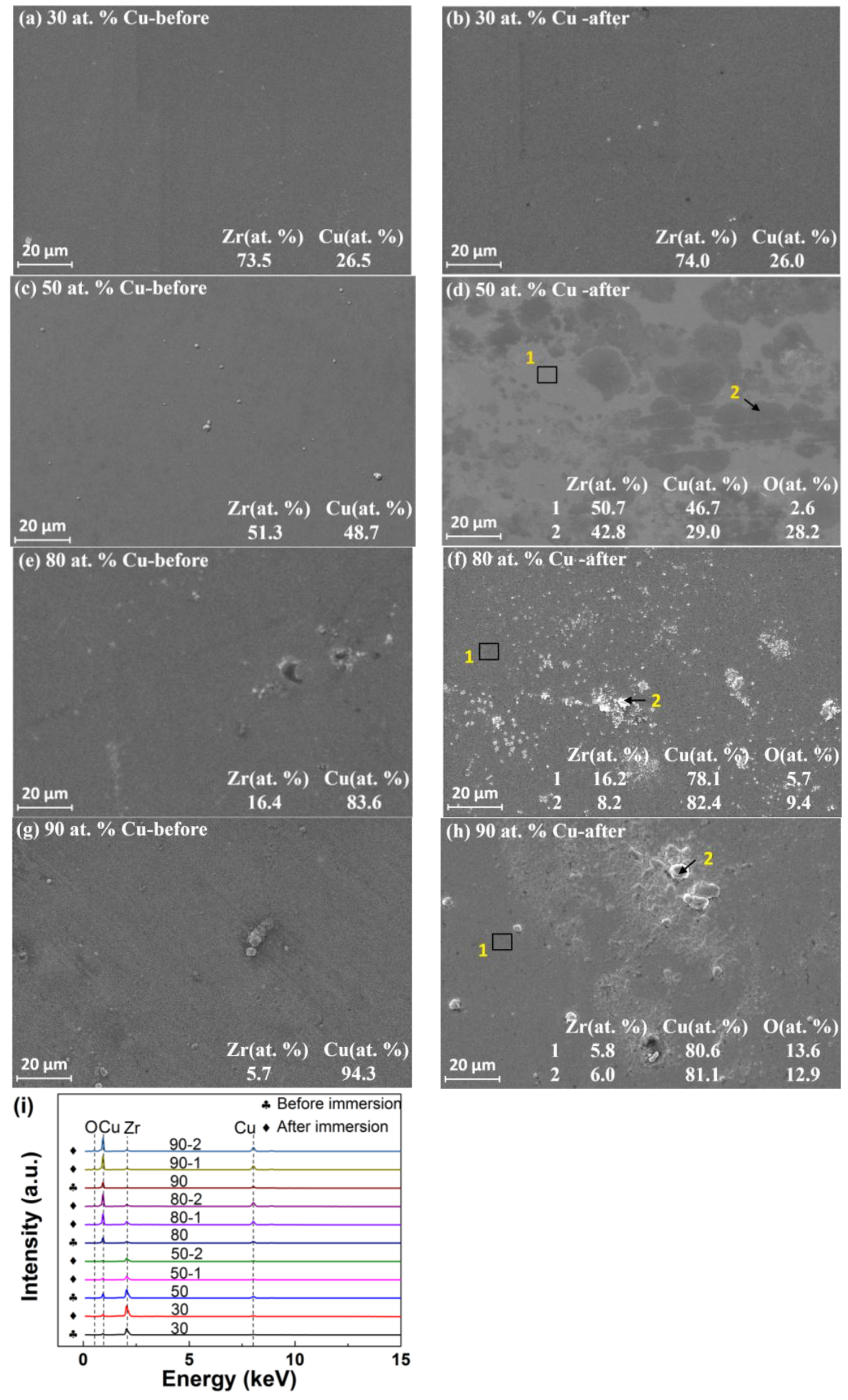

Figure 6. SEM images and energy dispersive analysis spectroscopy (EDS) results of Zr-Cu glassy coatings before and after corrosion for $16 \mathrm{~h}$ in $0.01 \mathrm{M}$ deaerated $\mathrm{H}_{2} \mathrm{SO}_{4}$ solution at ambient temperature; (a,b) Zr-30 at.\%Cu; (c,d) Zr-50 at.\% Cu; (e,f) Zr-80 at.\% Cu; (g,h) Zr-90 at.\% Cu; (i) EDS.

Moreover, it is interesting to note that the surface morphology of the $\mathrm{Zr}-80$ at.\% Cu sample changed significantly after corrosion (Figure 6e,f). Some white particles appeared on the surface in which the $\mathrm{Zr}$ content is much lower as compared with the smooth regions (zone 1 in Figure $6 \mathrm{f}$ ). 
The higher copper and oxygen contents in zone 2 indicate that these white particles are composed mainly of $\mathrm{CuO}$. It can also be noted that the $\mathrm{Zr} / \mathrm{Cu}$ proportion in the smooth zones (zone 1 in Figure $6 \mathrm{f}$ ) increased after immersion. This phenomenon may be associated with the selective corrosion of copper and the enrichment of zirconium in the surface.

Lastly, the SEM morphology of the Zr-90 at.\% Cu glassy coating sample after immersion (Figure 6h) highlights the fact that the surface endured dramatic corrosion compared with Figure $6 \mathrm{~g}$. The EDS measurements confirmed the decrease of the copper content and the increase of oxygen after corrosion, as compared with the as-deposited state.

\subsection{XPS Analysis}

XPS measurements were performed to analyze the chemical state and quantify the chemical composition of the surface of the $\mathrm{Zr}$-Cu glassy coatings. Figure 7 illustrates high-resolution spectra of the $\mathrm{Zr} 3 d$ (a), $\mathrm{Cu} 2 p_{3 / 2}$ (b) and $\mathrm{O} 1 s$ (c) after immersion for $12 \mathrm{~h}$ in $0.01 \mathrm{M}$ deaerated $\mathrm{H}_{2} \mathrm{SO}_{4}$ solution. The $\mathrm{C} 1$ s peak (binding energy of $284.8 \mathrm{eV}$ ) is derived from carbon contamination and was employed to calibrate the binding energies of the other elements.

The high intensity of the $\mathrm{Zr} 3 d$ and $\mathrm{O} 1$ s (Figure $7 \mathrm{a}, \mathrm{c}$ ) peaks recorded for the $\mathrm{Zr}-30$ at.\% Cu sample indicates the formation of a highly protective $\mathrm{ZrO}_{2}$ passive film in diluted $\mathrm{H}_{2} \mathrm{SO}_{4}$ solution. By contrast, the surface of the $\mathrm{Zr}-90$ at.\% sample consists of abundant metallic copper atoms and copper oxide. The content of $\mathrm{CuO}$ increases with the increase of copper in the sample, as indicated in Figure 7c.
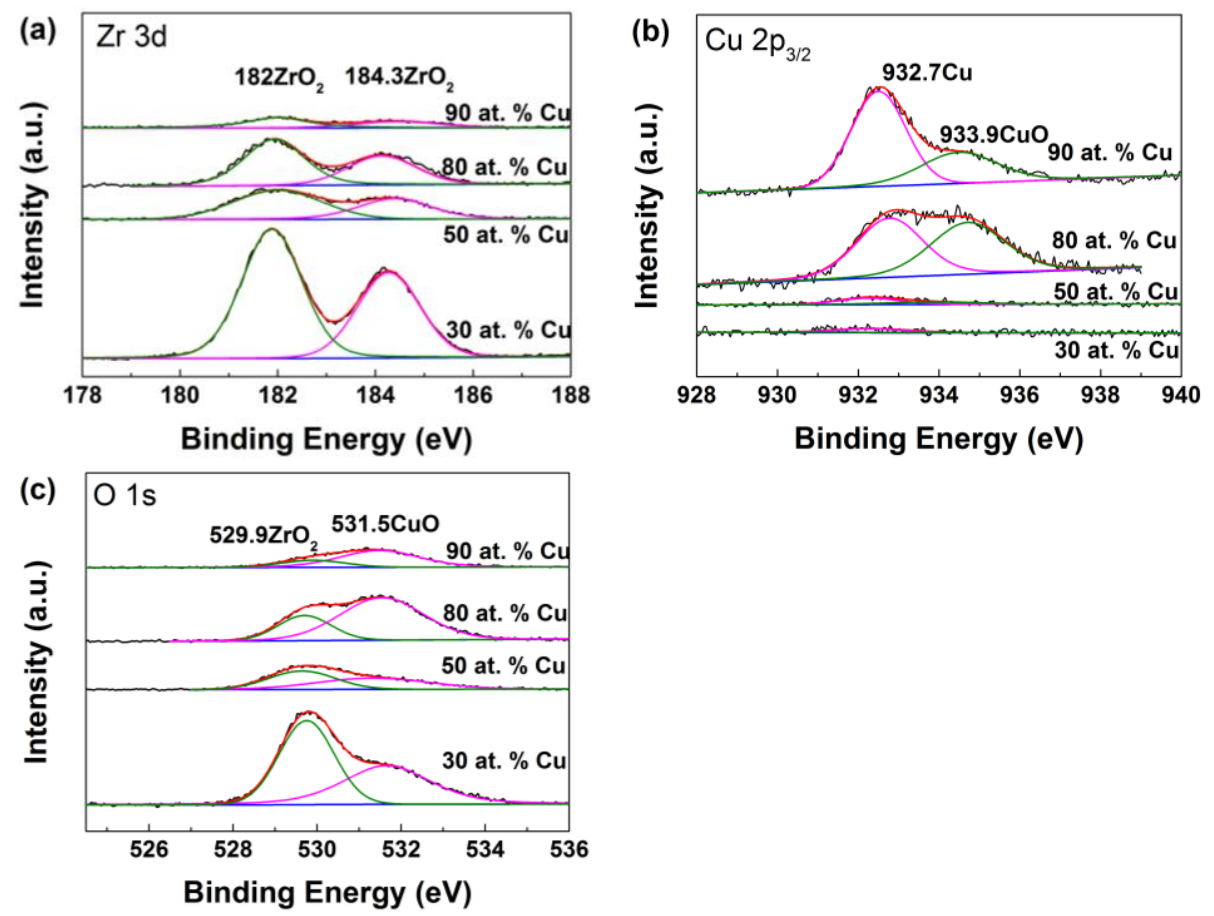

Figure 7. X-ray photoelectron spectroscopy (XPS) spectra of the Zr-Cu glassy coatings after immersion in $0.01 \mathrm{M}$ deaerated $\mathrm{H}_{2} \mathrm{SO}_{4}$ solution for $16 \mathrm{~h}$ at ambient temperature; (a) $\mathrm{Zr} 3 d$; (b) $\mathrm{Cu} 2 p_{3 / 2}$; (c) $\mathrm{O} 1 \mathrm{~s}$.

In order to further clarify the composition of the passive films or corrosion products, the atomic concentrations of each element were calculated by the convolution method according to each peak area and the relative sensitivity factors of elements (Figure 8). It has been found that the $\mathrm{Zr}$-Cu glassy coatings with enough zirconium content (not less than 50 at.\%) in the matrix had only minor copper (less than 5 at.\%) in the surface after immersion. This indicates a good formation ability of $\mathrm{ZrO}_{2}$ passive film on the surface. As the copper content increases in the glassy matrix, the copper atomic percentage on the surface increases. The $\mathrm{Zr} / \mathrm{Cu}$ ratio is approximately 4 when copper in the glassy matrix is around 80 at.\%. This implies that the $\mathrm{ZrO}_{2}$ film is not continuously formed on the surface. 
Even when the copper content reaches 90 at.\% in the glassy matrix, the percentage of copper is still lower compared with zirconium on the surface. The enrichment of zirconium on the surface is due to the preferential dissolution of copper, a phenomenon that has been observed in Fe-20Cr- $x \mathrm{Cu}$ alloy [28]. However, glassy coatings could not passivate if the $\mathrm{ZrO}_{2}$ film cannot cover most of the surface after the preferential dissolution of copper.

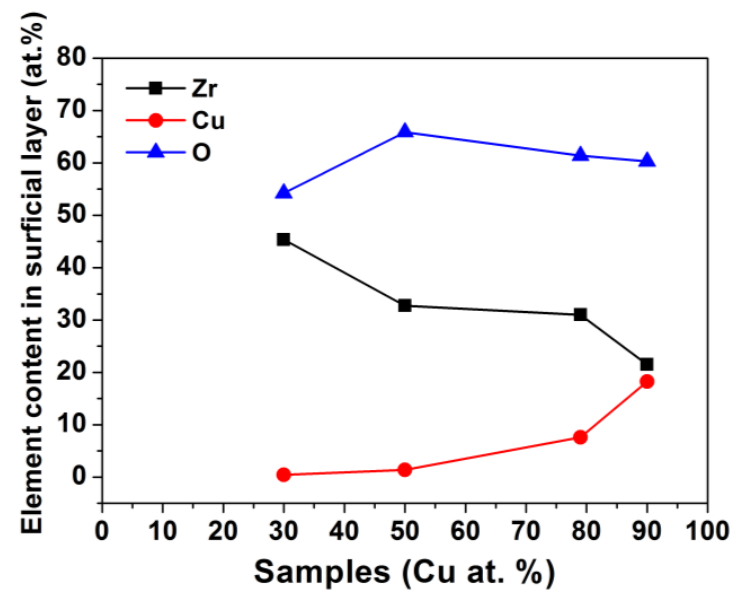

Figure 8. The element content of surficial layers of Zr-Cu glassy coatings by XPS.

\subsection{The $\mathrm{Cu}$ Content Impact on Mechanical Properties and impedance}

Figure 9 shows the effects of the $\mathrm{Cu}$ content on the mechanical properties and the overall resistance of impedance $\left(R_{o}\right.$, defined as $R_{c t}+R_{p}$, calculated from EIS results in Figure 4 by using the equivalent electrical circuit models in Figure 5). As the copper content increases in the $\mathrm{Zr}-\mathrm{Cu}$ matrix, the Young's modulus follows nearly a linear evolution with values in between $86 \mathrm{GPa}$ for the $\mathrm{Zr}-30$ at.\% Cu and $120 \mathrm{GPa}$ for the $\mathrm{Zr}-90$ at.\% Cu sample, respectively. This linear relationship may be related to the shrinking of the average interatomic distances [18]. The hardness increases from about 5 GPa for the $\mathrm{Zr}-30$ at.\% Cu sample to the maximum value of $6.7 \mathrm{GPa}$ for the $\mathrm{Zr}-80$ at. $\% \mathrm{Cu}$ sample. The results are in good agreement with other experimental investigations on $\mathrm{Zr}-\mathrm{Cu}$ metallic glass coatings [18]. It was reported that in the $\mathrm{Zr}-\mathrm{Cu}$ system the hardness has a maximum near the 60 at. $\% \mathrm{Cu}$ region due to the highest atomic packing density and minimum free volume $(\Delta V)$ [29]. On the other hand, the overall resistance $R_{o}$ decreased with the increase of copper content from $10^{7} \Omega \cdot \mathrm{cm}^{-2}$ to $10^{3} \Omega \cdot \mathrm{cm}^{-2}$, and passivation $\left(R_{o} \geq 10^{6} \Omega \cdot \mathrm{cm}^{-2}\right)$ is attainable when the content of zirconium is higher than 40 at.\% in the sample.

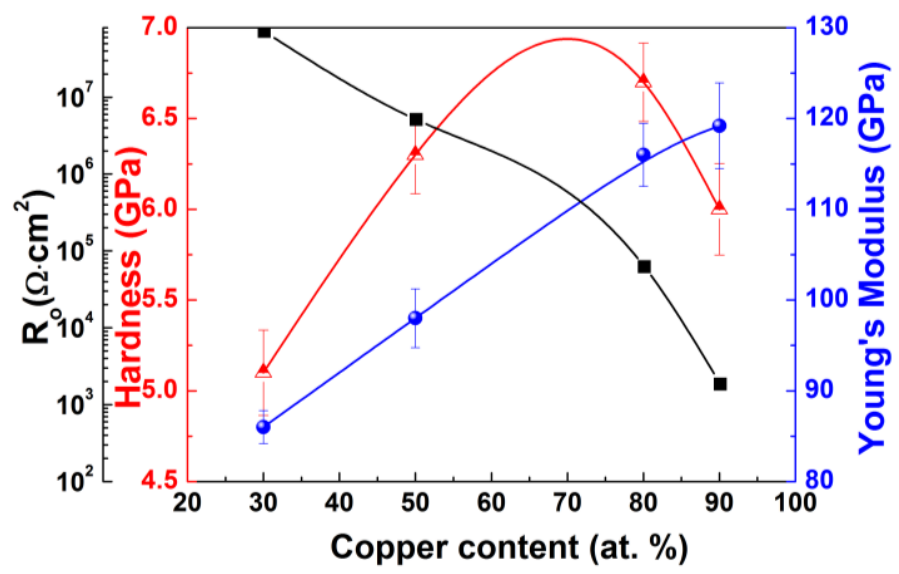

Figure 9. Composition dependence on mechanical properties and $R_{c t}$ value of the $\mathrm{Zr}$-Cu glassy coatings. 


\section{Discussion}

Figure 10 shows the changes of $R_{c t}$ and $Q$ values as functions of the immersion time. It can be observed clearly from Figure 10 a that the $R_{c t}$ values of the $\mathrm{Zr}-30$ at.\% $\mathrm{Cu}$ and $\mathrm{Zr}-50$ at.\% Cu samples increases slightly with immersion time evolution, denoting the formation and growth of $\mathrm{ZrO}_{2}$ passive film on the surface of these two samples. Two aspects determine their passivation property. The first is the dissolution of copper at the beginning of immersion that can lead to the enrichment of zirconium on the surface, which makes the formation of $\mathrm{ZrO}_{2}$ passive film on the surface possible. The second is that the generated $\mathrm{ZrO}_{2}$ passive film should have a good coverage degree on the surface to prevent the further dissolution of copper in the glassy coating. By contrast, for the $\mathrm{Zr}-80$ at.\% Cu and Zr-90 at.\% $\mathrm{Cu}$ samples, a different tendency is observed. Their $R_{c t}$ values decreased with respect to immersion time due to a non-continuous and non-compact $\mathrm{ZrO}_{2}$ layer being able to prevent the dissolution of copper in the glassy coating.
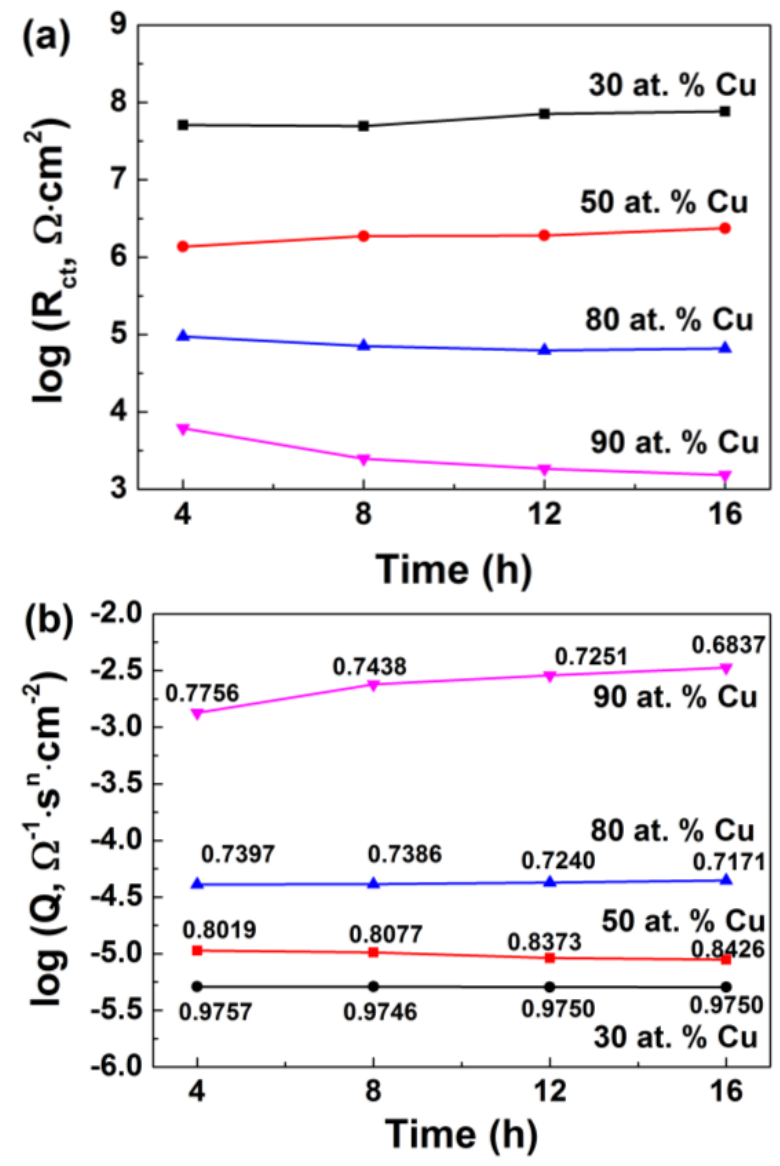

Figure 10. $R_{c t}$ and $Q$ values versus time plots of $\mathrm{Zr}-\mathrm{Cu}$ glassy coatings within $16 \mathrm{~h}$; (a) $R_{c t}$ values; (b) $Q$ values; the digits are the fitted $n$ values.

The $Q$ is related to the surface roughness, inhomogeneous spatial distribution of reaction sites and the inherent heterogeneous nature of the substrate [30]. Figure 10b shows that the values of $Q$ increased with the increase of $\mathrm{Cu}$ content, denoting that the electrochemical reaction kinetics increased. It also indicates that the surface roughness of the metallic glass coatings increased with the increase of $\mathrm{Cu}$ content according to Equation (1), which is consistent with the surface morphology changes illustrated in Figure 6. Furthermore, the value of $n$ decreased with the increase of $\mathrm{Cu}$ content. This indicates that the electrochemical process at the coating/electrolyte interface tends to change from electrochemical control to mixed control (electrochemical reaction and diffusion). 
On the other hand, the electrode potential of $\mathrm{Zr}\left(-1.904 \mathrm{~V}_{\mathrm{MMSE}}\right)$ is lower compared with $\mathrm{Cu}\left(-0.038 \mathrm{~V}_{\mathrm{MMSE}}\right)$, and the preferential oxidation of a metal in an alloy can be determined by the standard electrode potential [31,32]. Hence, the zirconium in the $\mathrm{Zr}-\mathrm{Cu}$ glassy coatings would be preferentially oxidized and a stable $\mathrm{ZrO}_{2}$ layer is formed. It is therefore clear that the corrosion resistance of the $\mathrm{Zr}-\mathrm{Cu}$ films depends on the coverage rate of $\mathrm{ZrO}_{2}$ protective film on the surface. KkochNim et al. also confirmed that a high content of $\mathrm{Cu}$ in passivable alloys decreases the stability of passive film in $\mathrm{H}_{2} \mathrm{SO}_{4}$ solution [28]. Since $\mathrm{CuO}$ is not stable in acid solutions [33], it cannot contribute to the formation of a protective layer.

Figure 11 illustrates the schematic models of the interface of the $\mathrm{Zr}-\mathrm{Cu}$ glassy coatings in $0.01 \mathrm{M}$ deaerated $\mathrm{H}_{2} \mathrm{SO}_{4}$ solution. As confirmed by the chemical analysis (Figures 6 and 8) and SEM morphologies (Figure $6 \mathrm{a}-\mathrm{h}$ ), the surface of the $\mathrm{Zr}-30$ at.\% $\mathrm{Cu}$ glassy coatings is completely covered by a protective passive film mainly consisting of $\mathrm{ZrO}_{2}$ (Figure 11a). Since slight corrosion occurred in local areas (the darker region in Figure $6 \mathrm{~d}$ ) on the surface after immersion, the coverage degree of the protective layer for the $\mathrm{Zr}-50$ at.\% Cu glassy coating (Figure 11b) is lower than that of the $\mathrm{Zr}-30$ at.\% $\mathrm{Cu}$ glassy coatings at the beginning. However, the increase of impedance arcs with the immersion time evolution (Figure $4 a$ a) reveals that the surface can passivate spontaneously but slowly. This is probably because after the oxidation-dissolution and the rearrangement of copper atoms in those corroded regions, the enrichment of zirconium is able to generate stable $\mathrm{ZrO}_{2}$ passive film to prevent further corrosion in such local areas. As a result, the $\mathrm{Zr}-50$ at. \% Cu glassy coating still exhibit good corrosion resistance.

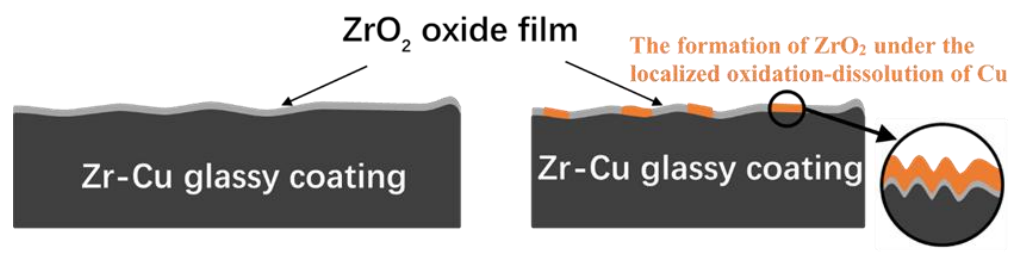

(a)

(b)

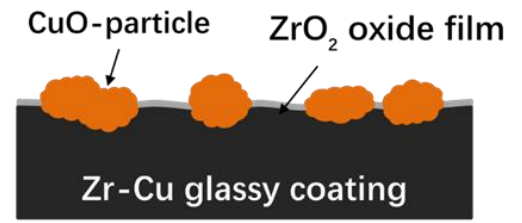

(c)

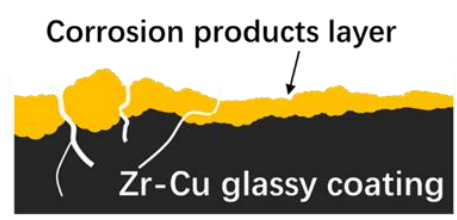

(d)

Figure 11. Surface morphologies models of $\mathrm{Zr}-\mathrm{Cu}$ glassy coating corrosion for $16 \mathrm{~h}$ in $0.01 \mathrm{M}$ deaerated $\mathrm{H}_{2} \mathrm{SO}_{4}$ solution at ambient temperature; (a) $\mathrm{Zr}-30$ at.\% Cu; (b) $\mathrm{Zr}-50$ at.\% Cu; (c) $\mathrm{Zr}-80$ at.\% Cu; (d) $\mathrm{Zr}-90$ at. $\% \mathrm{Cu}$.

For the $\mathrm{Zr}-80$ at.\% Cu glassy coating (Figure 11c), the $\mathrm{ZrO}_{2}$ passive film formed on the surface may be not continuous and presents many porosities. There are many $\mathrm{CuO}$ particles on the surface generated by corrosion, as confirmed by SEM micrographs (Figure 6f). Furthermore, considering the equivalent circuit diagram shown in Figure $5 b$, the copper-rich region is more susceptible to attack during corrosion and, accordingly, in this region a faster chemical reaction would take place. When the content of copper is much higher with respect to zirconium, severe corrosion occurred for the $\mathrm{Zr}-90$ at.\% Cu sample (Figure 11d). As a result, the corrosion product consisting mainly of $\mathrm{CuO}$ was formed on the surface.

Besides the chemical composition, the atomic structure of $\mathrm{Zr}-\mathrm{Cu}$ glassy coatings would influence the relationship between the corrosion and mechanical proprieties. However, in this particular metallic-glass system the atomic structure is essentially determined by the chemical state. 
In terms of mechanical properties, it has been demonstrated that for the binary $\mathrm{Zr}-\mathrm{Cu}$ alloying system, the atomic packing density increased until a maximum of around 65 at.\% Cu, at which a minimum relative free volume and maximum yield strength have been reported $[29,34]$. The mechanical properties of our $\mathrm{Zr}-\mathrm{Cu}$ glassy coatings (Figure 9) confirm that lower free volume density enhance the hardness and Young's modulus as a function of copper content $[35,36]$. Therefore, the free volume seems to have an effect on the mechanical properties of metallic glass [37], while on corrosion resistance this effect has not yet been elucidated in prior studies [38]. Poor passivation of $\mathrm{Zr}_{48} \mathrm{Cu}_{36} \mathrm{Ag}_{8} \mathrm{Al}_{8}$ glassy alloy due to active dissolution of $\mathrm{Cu}$ was reported for a high-energy metastable state with a relatively high amount of free volume [39]. That is to say, by reducing the amount of free volume in the $\mathrm{Cu}$-rich amorphous systems, the passivation behavior may be improved.

In the present paper, the correlation between nominal composition, interface composition, mechanical properties and corrosion resistance indicates that the $\mathrm{Cu}$ content may be not the only factor influencing corrosion resistance. A decrease in free volume would be expected to reduce the corrosion kinetics from a bond cleavage energy perspective.

However, it is unclear if the decrease in free volume would accelerate the active dissolution of copper or make the passivation of zirconium easier. In fact, the competition between these two processes depends significantly on the $\mathrm{Zr} / \mathrm{Cu}$ ratio. In this investigated $\mathrm{Zr}-\mathrm{Cu}$ system, because the content of copper is mostly higher than $50 \%$, the acceleration of copper dissolution may be the dominant process.

The effect of free volume is a factor to be considered, but may be secondary compared with chemical composition when considering the alloy's corrosion resistance. Finally, the correlations presented in Figure 9 may be used to design the best balance between corrosion resistance and mechanical properties in the preparation of $\mathrm{Zr}-\mathrm{Cu}$ glassy coatings.

\section{Conclusions}

The structure, morphology and electrochemical corrosion behavior of binary $\mathrm{Zr}_{100-x} \mathrm{Cu}_{x}(x=30$, $50,80,90$ at.\%) metallic glass coatings in $0.01 \mathrm{M}$ deaerated $\mathrm{H}_{2} \mathrm{SO}_{4}$ solution at ambient temperature were investigated, and some conclusions are:

1. The $\mathrm{Zr}-\mathrm{Cu}$ glassy coatings displayed a typical amorphous state with some traces of crystallinity for the $\mathrm{Zr}-90$ at.\% $\mathrm{Cu}$ sample composed of the pure $\mathrm{Cu}$ phase.

2. The metallic glassy coatings exhibited different corrosion resistance and corroded surface morphologies with respect to copper content. The corrosion current density increased and the EIS impedance of the $\mathrm{Zr}$-Cu glassy coatings decreased by increasing the copper content.

3. The $\mathrm{ZrO}_{2}$ formed on the surface benefited the formation of passive film, but the protection performance depended on the coverage degree of the $\mathrm{ZrO}_{2}$ oxide on the surface. The competition between the oxidation of $\mathrm{Zr}$ atoms $\left(\mathrm{ZrO}_{2}\right.$ film generation) and the oxidation-dissolution of $\mathrm{Cu}$ atoms assumed the most important role in the electrochemical behavior of the $\mathrm{Zr}-\mathrm{Cu}$ systerm. It also determined the interface micro-configuration.

4. The best mechanical properties of $\mathrm{Zr}-\mathrm{Cu}$ have been achieved at the values of $70-80 \mathrm{at} . \% \mathrm{Cu}$. However, the $\mathrm{Zr}-30$ at.\% Cu sample had the best corrosion resistance and displayed a stable passivation ability at a large polarization potential range. In addition, the evolution of free volume affected both the mechanical properties and corrosion behavior of the $\mathrm{Zr}-\mathrm{Cu}$ glassy coating.

Acknowledgments: This investigation is financially supported by the National Natural Science Foundation of China under grant No. 51401173, No. 51601158, and the Qihang Science Research foundation of Southwest Petroleum University, No. 2014QHZ014.

Author Contributions: Junlei Tang and Mihai Apreutesei conceived and designed the experiments; Qiuhong Zhu performed the experiments; Junlei Tang, Yingying Wang, Qiuhong Zhu, Mihai Apreutesei, Hu Wang and Mohamad Chamas analyzed the data; Philippe Steyer and Alain Billard contributed materials; Junlei Tang, Yingying Wang, Qiuhong Zhu and Mihai Apreutesei wrote the paper.

Conflicts of Interest: The authors declare no conflicts of interest. 


\section{References}

1. Qiao, J.W.; Jia, H.L.; Liaw, P.K. Metallic glass matrix composites. Mater. Sci. Eng. R 2016, 100, 1-69. [CrossRef]

2. Wang, W.H.; Dong, C.; Shek, C.H. Bulk metallic glasses. Mater. Sci. Eng. R 2004, 44, 45-89. [CrossRef]

3. Ashby, M.F.; Greer, A.L. Metallic glasses as structural materials. Scr. Mater. 2006, 54, 321-326. [CrossRef]

4. Hashimoto, K. Chapter 24-Chemical properties. In Amorphous Metallic Alloys; Elsevier: Amsterdam, The Netherlands, 1983; pp. 471-486.

5. Naka, M.; Hashimoto, K.; Masumoto, T. Corrosion behavior of amorphous and crystalline $\mathrm{Cu}_{50} \mathrm{Ti}_{50}$ and $\mathrm{Cu}_{50} \mathrm{Zr}_{50}$ alloys. J. Non-Cryst. Solids 1978, 30, 29-36. [CrossRef]

6. Turn, J.C.; Latanision, R.M. The influence of structure on the corrosion of glassy copper-zirconium alloys. Natl. Assoc. Corros. Eng. 1983, 39, 271-279. [CrossRef]

7. Bala, H.; Szymura, S. Acid corrosion of amorphous and crystalline Cu-Zr alloys. Appl. Surf. Sci. 1988, 35, 41-51. [CrossRef]

8. Gostin, P.F.; Eigel, D.; Grell, D.; Eckert, J.; Kerscher, E.; Gebert, A. Comparing the pitting corrosion behavior of prominent Zr-based bulk metallic glasses. J. Mater. Res. 2015, 30, 233-241. [CrossRef]

9. Axinte, E. Metallic glasses from "alchemy" to pure science: Present and future of design, processing and applications of glassy metals. Mater. Des. 2012, 35, 518-556. [CrossRef]

10. Lu, B.F.; Li, J.F.; Kong, L.T.; Zhou, Y.H. Correlation between mechanical behavior and glass forming ability of Zr-Cu metallic glasses. Intermetallics 2011, 19, 1032-1035. [CrossRef]

11. Schuh, C.A.; Hufnagel, T.C.; Ramamurty, U. Mechanical behavior of amorphous alloys. Acta Mater. 2007, 55, 4067-4109. [CrossRef]

12. Ghidelli, M.; Gravier, S.; Blandin, J.J.; Djemia, P.; Mompiou, F.; Abadias, G.; Raskin, J.P.; Pardoen, T. Extrinsic mechanical size effects in thin ZrNi metallic glass films. Acta Mater. 2015, 90, 232-241. [CrossRef]

13. Guo, L.J. Recent progress in nanoimprint technology and its applications. J Phys. D Appl. Phys. 2004, 37, 123-141. [CrossRef]

14. Kobata, J.; Miura, K.; Amiya, K.; Fukuda, Y.; Saotome, Y. Nanoimprinting of Ti-Cu-based thin-film metallic glasses deposited by unbalanced magnetron sputtering. J. Alloys Compd. 2017, 15, 132-136. [CrossRef]

15. Chu, J.P.; Jang, J.S.C.; Huang, J.C.; Chou, H.S.; Yang, Y.; Ye, J.C.; Wang, Y.C.; Lee, J.W.; Liu, F.X.; Liaw, P.K.; et al. Thin film metallic glasses: Unique properties and potential applications. Thin Solid Films 2012, 520, 5097-5122. [CrossRef]

16. Ghidelli, M.; Gravier, S.; Blandin, J.J.; Pardoen, T.; Raskin, J.J.; Mompiou, F. Compositional-induced structural change in $\mathrm{Zr}_{x} \mathrm{Ni}_{100-x}$ thin film metallic glasses. J. Alloys Compd. 2014, 615, 12-16. [CrossRef]

17. Apreutesei, M.; Steyer, P.; Joly-Pottuz, L.; Billard, A.; Qiao, J.; Cardinal, S.; Sanchette, F.; Pelletier, J.M.; Esnouf, C. Microstructural, thermal and mechanical behavior of co-sputtered binary $\mathrm{Zr}-\mathrm{Cu}$ thin film metallic glasses. Thin Solid Films 2014, 561, 53-59. [CrossRef]

18. Zeman, P.; Zítek, M.; Zuzjaková, Š.; Čerstvý, R. Amorphous Zr-Cu thin-film alloys with metallic glass behavior. J. Alloys Compd. 2017, 696, 1298-1306. [CrossRef]

19. Kondoh, K.; Fujita, J.; Umeda, J.; Serikawa, T. Estimation of compositions of Zr-Cu binary sputtered film and its characterization. Adv. Mater. Sci. Eng. 2008, 4, 1-5. [CrossRef]

20. Lu, H.B.; Li, Y.; Wang, F.H. Corrosion behavior and porous structure formation of sputtered Cu- $\mathrm{Zr}$ nanostructured films. J. Alloys Compd. 2008, 465, 139-144. [CrossRef]

21. Apreutesei, M.; Boissy, C.; Mary, N.; Arab Pour Yazdi, M.; Billard, A.; Steyer, P. Binary Zr-Ni/Co metallic glass films: Role of the structural state on their durability. Acta Mater. 2015, 89, 305-314. [CrossRef]

22. Del Re, M.; Gouttebaron, R.; Dauchot, J.P.; Leclère, P.; Terwagne, G.; Hecq, M. Study of ZrN layers deposited by reactive magnetron sputtering. Surf. Coat. Technol. 2003, 175, 240-245. [CrossRef]

23. Yu, S.H.; Yang, W.H.; Li, L.X.; Zhang, W.F. Improved chemical stability of ITO transparent anodes with a $\mathrm{SnO}_{2}$ buffer layer for organic solar cells. Sol. Energy Mater. Sol. Cells 2016, 144, 652-656. [CrossRef]

24. Apreutesei, M.; Steyer, P.; Billard, A.; Joly-Pottuz, L.; Esnouf, C. Zr-Cu thin film metallic glasses: An assessment of the thermal stability and phases' transformation mechanisms. J. Alloys Compd. 2015, 619, 284-292. [CrossRef]

25. Zhang, D.Q.; Gao, L.X.; Zhou, G.D. Inhibition of copper corrosion by bis-(1,1'-benzotriazoly)- $\alpha, \omega$-diamide compounds in aerated sulfuric acid solution. Appl. Surf. Sci. 2006, 252, 4975-4981. [CrossRef] 
26. Gebert, A.; Gostin, P.F.; Schultz, L. Effect of surface finishing of a Zr-based bulk metallic glass on its corrosion behavior. Corros. Sci. 2010, 52, 1711-1720. [CrossRef]

27. Merl, D.K.; Panjan, P.; Kovac, J. Corrosion and surface study of sputtered Al-W coatings with a range of tungsten contents. Corros. Sci. 2013, 69, 359-368. [CrossRef]

28. KkochNim, O.; Ihsan-UI-Haq, T.; SooHoon, A.; HyukSang, K. Effects of Cu on the passive film stability of $\mathrm{Fe}-20 \mathrm{Cr}-x \mathrm{Cu}\left(x=0,2,4\right.$ wt.\%) alloys in $\mathrm{H}_{2} \mathrm{SO}_{4}$ solution. Electrochim. Acta 2013, 88, 170-176. [CrossRef]

29. Park, K.W.; Jang, J.; Wakeda, M.; Shibutani, Y.; Lee, J.C. Atomic packing density and its influence on the properties of Cu-Zr amorphous alloys. Scr. Mater. 2007, 57, 805-808. [CrossRef]

30. Qin, F.X.; Wang, X.M.; Xie, G.Q.; Wada, K.; Song, M.; Furuya, K.; Asami, K.; Inoue, A. Microstructure and electrochemical behavior of Ti-coated $\mathrm{Zr}_{55} \mathrm{Al}_{10} \mathrm{Ni}_{5} \mathrm{Cu}_{30}$ bulk metallic glass. Intermetallics 2009, 17, 945-950. [CrossRef]

31. Paunovic, M.; Schlesinger, M. Equilibrium Electrode Potential. In Fundamentals of Electrochemical Deposition, 2nd ed.; Wiley-Interscience: Hoboken, NJ, USA, 2006.

32. Tan, M.; Liu, Q.; Zhang, N.; Hu, H.; Li, B.; Kang, X. Characterization of the surface film on Zr-based bulk metallic glass using X-ray photoelectron spectroscopy (XPS) and scanning electron microscopy (SEM). J. Alloys Compd. 2011, 509, 5926-5930. [CrossRef]

33. Amin, M.A.; Khaled, K.F. Copper corrosion inhibition in $\mathrm{O}_{2}$-saturated $\mathrm{H}_{2} \mathrm{SO}_{4}$ solutions. Corros. Sci. 2010, 52, 1194-1204. [CrossRef]

34. Kang, K.H.; Park, K.W.; Lee, J.C.; Fleury, E.; Lee, B.J. Correlation between plasticity and other materials properties of $\mathrm{Cu}-\mathrm{Zr}$ bulk metallic glasses: An atomistic simulation study. Acta Mater. 2011, 59, 805-811. [CrossRef]

35. Chen, L.Y.; Setyawan, A.D.; Kato, H.; Inoue, A.; Zhang, G.Q.; Saida, J.; Wang, X.D.; Cao, Q.P.; Jiang, J.Z. Free-volume-induced enhancement of plasticity in a monolithic bulk metallic glass at room temperature. Scr. Mater. 2008, 59, 75-78. [CrossRef]

36. Cao, Q.P.; Jin, J.B.; Ma, Y.; Cao, X.Z.; Wang, B.Y.; Qu, S.X.; Wang, X.D.; Zhang, D.X.; Jiang, J.Z. Enhanced plasticity in Zr-Cu-Ag-Al-Be bulk metallic glasses. J. Non-Cryst. Solids 2015, 412, 35-44. [CrossRef]

37. Apreutesei, M.; Billard, A.; Steyer, P. Crystallization and hardening of $\mathrm{Zr}-40$ at.\% Cu thin film metallic glass: Effects of isothermal annealing. Mater. Des. 2015, 86, 555-563. [CrossRef]

38. Tailleart, N.R.; Huang, R.; Aburada, T.; Horton, D.J.; Scully, J.R. Effect of thermally induced relaxation on passivity and corrosion of an amorphous Al-Co-Ce alloy. Corros. Sci. 2012, 59, 238-248. [CrossRef]

39. Jayaraj, J.; Gebert, A.; Schultz, L. Passivation behaviour of structurally relaxed $\mathrm{Zr}_{48} \mathrm{Cu}_{36} \mathrm{Ag}_{8} \mathrm{Al}_{8}$ metallic glass. J. Alloys Compd. 2009, 479, 257-261. [CrossRef] 